\title{
Editorial
}

Why a new journal about diplomacy? The answer relates to both the form and the substance of what diplomacy is and does.

Diplomatic history has had something of a tarnished reputation since at least the 1970s. A field that set itself the task of re-creating the mechanisms of inter-state relations by focusing on the archives of foreign ministries was facing something of a credibility crisis. States have continued to shape world order, but not as the only actors. Social history "from below" has rejected and looked beyond the elite-based focus of traditional diplomatic history. Economic history has broadened the context within which diplomatic decisions are taken. The subjectivities of emissaries and representatives of diplomacy have been dissected using race, class, and gender lenses. Post-colonial history has questioned the assumptions of Western norms and "origins" to diplomacy, pointing to other paths that were long written out of that normative history. Transnational history has highlighted the role of social movements and entanglements that undermine the notion of the unitary state. Global history has situated the local event within the wider scope of all-encompassing trends through time. Applied history has situated current events in a comparative setting in search of patterns and lessons. Contemporary history, as illustrated by this issue's Brexit forum, has done the opposite in tracing their origins and evolution in our own era.

Diplomatic history, faced with these waves of innovation by fellow historians, was seeing its raison d'être being undermined. Once regarded as an eminent branch of historical study, it has declined, and in some universities, even disappeared.

Yet, diplomacy has not disappeared as an essential tool with which to enable world politics to function. The decline of diplomatic history that began some fifty years ago was in part the result of a narrow, and in our view, misguided, view of diplomacy and its history. The array of those involved in these processes has since grown wider, giving space - however grudgingly at times to non-state actors. Just as another subfield to experience a decline - military history - is not the exclusive account of professional armies on battlefields, diplomatic history now involves much more - to recall the infamous slight than "what one clerk said to another." 
The critique has become the basis for a renaissance. Today, the study of diplomacy is no longer predominated by historians. Sociologists, anthropologists, human geographers, political scientists, ethnologists, psychologists, and linguists have begun to explore the meaning, function, and habitat (in Pierre Bourdieu's sense) of diplomacy and diplomatic actors from their respective methodological angles. International Relations theory long disregarded diplomacy as important, with only a few exceptions, notably the work of Martin Wight, Hedley Bull and the English School. Yet the "practice turn" in IR theory over the past decade now focuses on the "real world processes" of inter-state relations, that is, their diplomacy. The trends of research across a multitude of disciplines have been providing opportunities for methodological bridges to be built that can enrich the study of diplomacy through the ages.

This is the basic justification for a new journal that positions itself at the intersection of these many, varied, and rich paths of enquiry, with "diplomacy" as the signpost that links all lines of investigation; and for the inclusion, in our first issue, of a special forum featuring contributions from seven scholars three historians, two geographers, a political scientist, and a professor of comparative literature - on approaches to the study of diplomacy through time in their own work.

The juxtaposition of essays suggests, we hope, more commonalities than divergences. One of special importance relates to diplomacy's principal subjects. The above terms "international," "transnational," and "global" suggest the empirical validity for scholarship of anything, human or non-human, that crosses a border. But whose borders? This journal looks beyond national confines, which include but are not limited to the nation's role in defining cross-border relationships. Doing otherwise would presume to exclude empires, cities, and other bodies that are not, strictly speaking, national.

We prefer a broader term to designate the actors and "units" involved in diplomacy: polity. This is fluid enough to encompass a range of entities that would otherwise fall outside of, or be reduced to secondary status within, a state-led system. The state may or may not be primus inter pares among polities, depending on historical period, regional location, and type of activity. This in turn leads to a definition of diplomacy that is more functional than essential.

That definition means scholarship dedicated less to "bringing the state back in" than to seeing and understanding the extensive network of ties between state and non-state diplomatic actors in historical and social context, which extends to the historical chronology itself. We are interested less in events as "markers of world history" than in the latent personal and impersonal forces behind those events, and, most of all, in the rich interaction of one set of factors 
with another. This re-examination of how events are "assembled" necessarily also involves re-examining the subjectivities of the "clerks" to understand their training, social milieu, and world views. It reinterprets raison d'État to explore the many impulses that feed into a so-called national interest, with the recent interest in emotions through history a perfect example. It is about attempting to grasp the hybridity of diplomacy in all its forms, affects, and expressions over time.

Diplomacy thus relates to any action, setting, or phenomenon that represents the interests, status, actions, or behavior of a polity vis-à-vis another. Its agents may be individuals; groups; or official, quasi-official, and unofficial actors. Its manifestations may reflect as much change as continuity in method and result. However, it must do more than exist on multiple territories. It must act in some way to represent, condition, or determine the collective interrelationship of actors between and across such territories. And it must maintain the classic trilogy of their activity: information-gathering, communication, and negotiation.

Our journal's title, Diplomatica, with its root in the Greek for a folded object - from which "diplomacy" eventually evolved - provides the perfect tether for the merging of old and new, and of diverse actorship, that we seek. In so doing, we look to draw on and envelop the innovative approaches utilized by early modern historians to reconfigure and enrich our understanding of the modern era. This necessarily involves augmenting the Western model with alternative conceptions of diplomacy sidelined by the standard interpretations of modernity, and looking beyond English-speaking academia to incorporate the latest research trends generated in Singapore, Paris, Rio, Basel, Montreal, Berlin, and beyond. This orientation extends to what we hope, as we state in the journal's mission statement, will be a fruitful combination of two cultures in the humanities and the social sciences, namely, diplomatic history and diplomatic studies.

Combining so much carries risks, to be sure. One of them may be the challenge to our subjects' traditional effort to keep a low profile, for diplomacy, like diplomatic history, has tended to enjoin a condition of self-denial. Diplomats produce "non-papers"; they work "behind the scenes"; they rarely, on principle, promote themselves or their work in public. That wish has extended, perhaps perversely, to the study of their history, which, to recall Cardinal Richelieu's instruction for diplomatic negotiation, is better characterized by discreet continuity or "process" than by a standard chronology of tangible achievements. The study of diplomacy as ongoing process therefore breaks up the given sequence of actions, providing a different perspective on "what happened when." 
An end to self-denial is long overdue. Diplomacy requires a proper, and, in our view, prominent, scholarship. This means breaking down the barriers that positioned diplomacy as a sealed-off compartment in terms of the approaches of both foreign policy professionals and academic researchers. We see this to be, by necessity, an inter- and multi-disciplinary project, as well as one that relates to multiple subjects, regional locations, and time periods, in order to take best advantage of what have been to date piecemeal advances in the study of diplomacy and its long history. Hence, Diplomatica.

\section{Giles Scott-Smith}

Leiden University / Roosevelt Institute for American Studies g.scott-smith@hum.leidenuniv.nl

Kenneth Weisbrode

Bilkent University

weisbrode@bilkent.edu.tr 